\title{
不同熟期类型玉米品种籽粒灌浆和脱水特性
}

\author{
王荣焕 $^{* *}$ 徐田军 ${ }^{* *}$ 陈传永 王元东吕天放 刘月娥蔡万涛 \\ 刘秀芝赵久然*
}

北京市农林科学院玉米研究中心 / 玉米 DNA 指纹及分子育种北京市重点实验室, 北京 100097

摘 要: 根据自然生态条件及玉米品种的熟期、籽粒灌浆与脱水特性和产量潜力等进行科学品种布局, 是实现玉米 高产优质和资源高效利用的重要途径。本试验选用中早熟、中熟和中晚熟 3 个熟期类型, 共 13 个玉米生产主栽品种, 通过测定籽粒干物质积累和含水率的动态变化, 研究并明确了不同熟期类型玉米品种的籽粒灌浆和脱水特性, 旨 在为生产品种布局提供参考和指导。试验结果表明: 产量、籽粒灌浆和脱水特性在不同熟期类型和品种间均存在 显著差异。产量表现为中晚熟 $\left(13,813.0 \mathrm{~kg} \mathrm{hm}^{-2}\right)>$ 中熟 $\left(12,970.4 \mathrm{~kg} \mathrm{hm}^{-2}\right)>$ 中早熟品种 $\left(10,729.0 \mathrm{~kg} \mathrm{hm}^{-2}\right)$, 中晚 熟分别较中早熟和中熟品种增产 $28.7 \%$ 和 $6.5 \%$ 。平均灌浆速率表现为中早熟 $\left(0.034 \mathrm{~g} 100-\mathrm{grain}^{-1}{ }^{\circ} \mathrm{C}^{-1}\right)>$ 中熟 $(0.031$ g 100-grain $\left.{ }^{-1}{ }^{\circ} \mathrm{C}^{-1}\right)>$ 中晚熟品种 $\left(0.027 \mathrm{~g} 100-\right.$ grain $\left.^{-1}{ }^{\circ} \mathrm{C}^{-1}\right)$, 生理成熟后的平均物理脱水速率表现为中熟 $(0.027 \%$ $\left.{ }^{\circ} \mathrm{C}^{-1} \mathrm{~d}^{-1}\right)>$ 中早熟 $\left(0.025 \%{ }^{\circ} \mathrm{C}^{-1} \mathrm{~d}^{-1}\right)>$ 中晚熟品种 $\left(0.018 \%{ }^{\circ} \mathrm{C}^{-1} \mathrm{~d}^{-1}\right)$ 。中早熟代表性品种京农科 728 的平均灌浆速率 和生理成熟后的物理脱水速率。分别较 3 个熟期代表性品种郑单 958、先玉 335 、农华 101 高 $38.5 \%$ 和 $112.5 \%$ 、 $28.6 \%$ 和 $54.5 \%$ 、28.6\%和 $13.3 \%$; 中晚熟代表性品种京科 968 产量潜力最大 $\left(14,813.0 \mathrm{~kg} \mathrm{hm}^{-2}\right)$, 且平均灌浆速率和 物理脱水速率分别较同熟期品种郑单 958 高 $7.7 \%$ 和 $18.8 \%$ 。产量与灌浆期天数、积温、平均灌浆速率和百粒重呈 显著或极显著正相关, 收获期籽粒含水率与灌浆期天数和积温显著正相关、与生理降水速率和物理脱水速率极显 著负相关, 生理降水速率和物理脱水速率与平均灌浆速率相关性不显著。综上, 中早熟、中熟和中晚熟 3 个不同 熟期类型及不同玉米品种的籽粒灌浆和脱水特性差异显著, 生产中品种布局除考虑熟期外还需兼顾该特性, 以更 利于实现玉米高产优质和资源高效利用。

关键词：玉米；熟期类型；籽粒灌浆特性；脱水特性

\section{Grain filling and dehydrating characteristics of maize hybrids with different maturity}

WANG Rong-Huan $^{* *}$, XU Tian-Jun ${ }^{* *}$, CHEN Chuan-Yong, WANG Yuan-Dong, LYU Tian-Fang, LIU Yue-E, CAI Wan-Tao, LIU Xiu-Zhi, and ZHAO Jiu-Ran*

Maize Research Center, Beijing Academy of Agriculture and Forestry Sciences / Beijing Key Laboratory of Maize DNA Fingerprinting and Molecular Breeding, Beijing 100097, China

\begin{abstract}
Suitable variety arrangement according to the natural ecological conditions, maturity, grain filling and dehydrating characteristics and yield potential of maize hybrid is an important approach for realizing higher maize yield, quality and photothermal resource utilization. Thirteen hybrids widely planted in maize production with three maturity types [medium-early maturity (MEM), medium maturity (MM) and medium-late maturity type (MLM)] were selected to clarify the grain filling and dehydrating characteristics for different maturity hybrids, by investigating the dynamic changes of grain filling and moisture content. The results showed that yield, grain filling and dehydrating characteristics differed significantly between different maturities and
\end{abstract}

\footnotetext{
本研究由国家现代农业产业技术体系建设专项(CARS-02)资助。

This study was supported by the China Agriculture Research System (CARS-02).

*通信作者(Corresponding author): 赵久然, E-mail: maizezhao@126.com, Tel: 010-51503936

** 同等贡献(Contributed equally to this work)

第一作者联系方式: 王荣焕, E-mail: ronghuanwang@126.com; 徐田军, E-mail: xtjxtjbb@163.com

Received (收稿日期): 2019-02-26; Accepted (接受日期): 2020-09-13; Published online (网络出版日期): 2020-09-22.

URL: https://kns.cnki.net/kcms/detail/11.1809.S.20200922.1344.014.html
} 
hybrids. Average yield level showed MLM $\left(13,813.0 \mathrm{~kg} \mathrm{hm}^{-2}\right)>\mathrm{MM}\left(12,970.4 \mathrm{~kg} \mathrm{hm}^{-2}\right)>\mathrm{MEM}\left(10,729.0 \mathrm{~kg} \mathrm{hm}{ }^{-2}\right)$, with MLM was $28.7 \%$ and $6.5 \%$ higher than that of MLM and MM type, respectively. Average grain filling rate showed MEM (0.034 $\mathrm{g}$ 100 -grain $\left.{ }^{-1}{ }^{\circ} \mathrm{C}^{-1}\right)>\operatorname{MM}\left(0.031 \mathrm{~g} \mathrm{100}\right.$-grain $\left.{ }^{-1}{ }^{\circ} \mathrm{C}^{-1}\right)>\operatorname{MLM}\left(0.027 \mathrm{~g} 100\right.$-grain $\left.{ }^{-1}{ }^{\circ} \mathrm{C}^{-1}\right)$, average dehydrating rate after physiological maturity (PM) showed MM $\left(0.027 \%{ }^{\circ} \mathrm{C}^{-1} \mathrm{~d}^{-1}\right)>\operatorname{MEM}\left(0.025 \%{ }^{\circ} \mathrm{C}^{-1} \mathrm{~d}^{-1}\right)>\operatorname{MLM}\left(0.018 \%{ }^{\circ} \mathrm{C}^{-1} \mathrm{~d}^{-1}\right)$. Average grain filling rate and dehydrating rate after PM of MEM representative hybrid Jingnongke 728 were $38.5 \%$ and $112.5 \%, 28.6 \%$ and 54.5\%, 28.6\% and $13.3 \%$ higher than those of representative hybrid Zhengdan 958, Xianyu 335 and Nonghua 101 for three maturity type; the yield of Jingke 968 was the highest $\left(14,813.0 \mathrm{~kg} \mathrm{hm}^{-2}\right)$, average grain filling rate and dehydrating rate after PM was7.7\% and $18.8 \%$ higher than the same maturity hybrid Zhengdan 958. Yield level was significantly or extremely significantly correlated with grain filling period, corresponding accumulated temperature, average grain filling rate and 100-grain weight; grain moisture content at harvest stage was significantly correlated with grain filling period and corresponding accumulated temperature, but negatively significantly correlated with dehydrating rate before and after PM; there were no significant correlation between dehydrating rate before and after PM with average grain filling rate. Maturity, grain filling and dehydrating characteristics were all important factors for higher maize yield, quality and photothermal resource utilization. This study indicated that maize grain filling and dehydrating characteristics differed significantly between different maturity types and hybrids. Maturity, grain filling and dehydrating characteristics should be well considered for variety arrangement in maize production in order to achieve higher maize yield, quality and photothermal resource utilization.

Keywords: maize; maturity type; grain filling characteristics; grain dehydrating characteristics

因地制宜合理品种布局，充分协调自然生态 条件、品种熟期与产量潜力以及栽培技术措施间 的关系，是实现资源高效利用和玉米高产优质的 重要途径。近年随着玉米生产目标由追求高产逐 步转变为高产、优质、高效协调统一, 以及玉米机 收技术的快速发展, 玉米品种的籽粒灌浆特别是 脱水特性得到了进一步重视, 并成为玉米研究领 域的热点之一 ${ }^{[1]}$ 。

大量研究表明, 玉米籽粒的灌浆及脱水特性与 产量和品质密切相关 ${ }^{[2-3]}$, 并受品种特性、生态环境 及栽培条件 ${ }^{[4-9]}$ 等共同影响。玉米籽粒的灌浆过程是 干物质积累和产量形成的过程, 粒重受灌浆速率和 灌浆持续时间影响 ${ }^{[10-11]}$; 玉米收获期籽粒含水率受 灌浆速率、生理成熟期含水量及生理成熟后脱水速 率共同影响 ${ }^{[12]}$ 。关于不同熟期类型玉米品种的籽粒 灌浆和脱水特性, 王同朝等 ${ }^{[13]}$ 研究表明中熟比中晚 熟品种灌浆速率高; 王晓慧等 ${ }^{[11]}$ 研究表明中熟品种 灌浆活跃期和有效灌浆时间短, 中晚熟、晚熟和超晚 熟品种灌浆活跃期和有效灌浆时间长; 钱春荣等 ${ }^{[14]}$ 研 究表明灌浆速率以中早熟品种最高、极早熟品种次 之, 中晚熟品种最低; 李凤海等 ${ }^{[15]}$ 研究表明, 中晚 熟品种平均脱水速率高于晚熟品种, 生理成熟时含 水率的高低影响收获时的含水率; 万泽花等 ${ }^{[16-17]}$ 研究 认为早熟较中晚熟品种脱水快。

关于不同熟期玉米品种的籽粒灌浆和脱水特性, 已有报道多是针对某一区域品种进行研究, 存在同 一品种在不同区域属于不同熟期类型, 且灌浆速率 多是基于粒重与授粉后天数进行拟合, 导致不同熟 期品种因籽粒灌浆和脱水处于不同环境(特别是温
度条件)而无法进行客观评价和比较。因此, 本文基 于国家玉米品种区域试验中对玉米品种熟期的界定 标准, 以积温作为玉米生育进程的估算指标, 以中 早熟、中熟和中晚熟 3 个熟期类型, 共13个玉米生产 主栽品种为试验材料, 研究了各品种籽粒干物质积 累和含水率的动态变化, 明确了不同熟期类型品种 的籽粒灌浆、脱水特性及产量潜力, 旨在为玉米生 产科学品种布局、实现玉米高产优质和资源高效利 用提供参考和指导。

\section{1 材料与方法}

\section{1 试验设计}

选用中早熟 (medium-early maturity type, MEM)、中熟(medium maturity type, MM)和中晚熟 (medium-late maturity type, MLM) 3 个熟期类型, 共 13 个玉米生产主推品种为试验材料(表 1)。在北京市 昌平区小汤山国家精准农业研究示范基地开展试验, 2015 年 5 月 10 日播种, 各品种分别于生理成熟后 $14 \mathrm{~d}$ 收获。试验小区随机区组排列, 3 次重复。小区 面积 $43.2 \mathrm{~m}^{2}, 12$ 行区、行长 $6 \mathrm{~m}$ 、行距 $0.6 \mathrm{~m}$ 。留苗 密度为 52,500 株 $\mathrm{hm}^{-2}$ 。其他管理同当地生产田。

\section{2 测定项目}

\subsection{1 生育进程准确调查记载各品种的出苗} 期、吐丝期、生理成熟期。

1.2.2 籽粒灌浆和脱水指标吐丝前, 分别选择 各品种生长健壮一致的代表性植株进行挂牌标记。 各品种均在授粉后 $15 \mathrm{~d}$ 起, 每隔7 d取样 1 次直至收 获。生理成熟期和收获期均分别取样。每次取样各 小区分别取 3 个果穗, 取果穗中部籽粒 100 粒, 称其 
鲜重, 在 $105^{\circ} \mathrm{C}$ 烘箱中杀青 $30 \mathrm{~min}$ 后, $80^{\circ} \mathrm{C}$ 烘干至恒 重, 测定各品种的百粒干重。参照李璐璐等 ${ }^{[1]}$ 的方法 计算籽粒灌浆和水分相关指标。

含水量 $(\mathrm{g})=$ 鲜重 $(\mathrm{g})-$ 千重 $(\mathrm{g})$

含水率 $(\%)=($ 含水量 $/$ 鲜重 $) \times 100$

生理成熟前籽粒平均脱水速率 $\left[\%\left({ }^{\circ} \mathrm{C} d\right)^{-1}\right]=$ $[90 \%-$ 生理成熟期籽粒含水率 $(\%)] /$ 授粉至生理成 熟积温 $\left({ }^{\circ} \mathrm{C} \mathrm{d}\right)$

生理成熟后籽粒平均脱水速率 $\left[\%\left({ }^{\circ} \mathrm{C} \mathrm{d}\right)^{-1}\right]=[$ 生 理成熟期籽粒含水率 $(\%)$ - 收获期籽粒含水率 $(\%)] /$ 生理成熟后积温 $\left({ }^{\circ} \mathrm{C} \mathrm{d}\right)$

籽粒脱水速率 $\left[\%\left({ }^{\circ} \mathrm{C} \mathrm{d}\right)^{-1}\right]=[90 \%$ - 收获期籽 粒含水率 $(\%)] /$ 总积温 $\left({ }^{\circ} \mathrm{C} \mathrm{d}\right)$

以授粉后积温 $\left({ }^{\circ} \mathrm{C}\right)$ 为自变量、授粉后每 $7 \mathrm{~d}$ 测得 的百粒重为因变量 $(W)$, 参照朱庆森等 ${ }^{[18]}$ 的方法, 利 用Richards方程 $W=A\left(1+B \mathrm{e}^{-C t}\right)^{-1 / D}$ 模拟籽粒灌浆过 程。籽粒灌浆速率: $F=A C B \mathrm{e}^{-C t} /\left(1+B \mathrm{e}^{-C t}\right)^{(D+1) / D}$, 式 中: $W$ 为粒重 $(\mathrm{g}), A$ 为最终粒重 $(\mathrm{g}), t$ 为授粉后积温 $\left({ }^{\circ} \mathrm{C}\right), B 、 C 、 D$ 为回归方程所确定的参数, 其中 $B$ 为初 值参数、 $C$ 为生长速率参数、 $D$ 为形状参数, 当 $D=1$ 时, 即为Logistic方程。
计算下列灌浆特征参数:

最大灌浆速率 $\left(G_{\max }\right)=\left(C W_{\max } / D\right)\left[1-\left(W_{\max } / A\right) D\right]$

平均灌浆速率 $\left(G_{\mathrm{ave}}\right)=A C /(2 D+4)$

灌浆活跃期积温(完成总积累量的 $90 \%$ 所需积温) $P=2(D+2) / C$

1.2.3 产量收获期, 剔除边行植株, 各小区人 工收获中间2行，自然风干后进行考种，测定穗行 数、行粒数、百粒重和籽粒含水率，并折算成 $14 \%$ 标 准含水率产量。

\section{3 数据处理}

采用 SAS 软件进行数据方差分析, 其中处理间 差异显著性采用 LSD 法进行检验 $(\alpha=0.05)$ 。通过 CurveExpert 3.0 软件进行籽粒含水率拟合, 采用 Microsoft Excel 2017 进行数据计算和作图。

\section{2 结果与分析}

\section{1 玉米品种的生育期}

试验结果表明，不同熟期类型玉米品种的生育 期、吐丝至生理成熟的天数及积温均存在较大差异 (表1)。从生育期来看, 中晚熟品种(均为 $121 \mathrm{~d}$ )分别 较中熟品种(平均 $114 \mathrm{~d} \pm 1.3 \mathrm{~d}$ )和中早熟品种(平均

表 1 供试玉米品种的生育期与积温

Table 1 Growth period and accumulated temperature of maize hybrids

\begin{tabular}{|c|c|c|c|c|c|c|}
\hline $\begin{array}{c}\text { 熟期类型 } \\
\text { Maturity type }\end{array}$ & $\begin{array}{c}\text { 品种 } \\
\text { Hybrid }\end{array}$ & $\begin{array}{c}\text { 吐丝期 } \\
\text { Silking } \\
\text { stage } \\
\text { (month/day) }\end{array}$ & $\begin{array}{c}\text { 生理成熟期 } \\
\text { Physiological } \\
\text { maturity } \\
\text { (month/day) }\end{array}$ & $\begin{array}{c}\text { 生育期 } \\
\text { Growing } \\
\text { period (d) }\end{array}$ & $\begin{array}{c}\text { 吐丝期-生理 } \\
\text { 成熟期天数 } \\
\text { Days from silking stage } \\
\text { to physiological } \\
\text { maturity (d) } \\
\end{array}$ & $\begin{array}{c}\text { 吐丝期-生理成熟期积温 } \\
\text { Accumulated temperature } \\
\text { from silking stage to } \\
\text { physiological } \\
\text { maturity }\left({ }^{\circ} \mathrm{C} \mathrm{d}\right) \\
\end{array}$ \\
\hline 中早熟类型 & 吉单 27 Jidan 27 & $7 / 9$ & $9 / 1$ & 107 & 54 & 1406.5 \\
\hline \multirow{2}{*}{$\begin{array}{l}\text { Medium-early } \\
\text { maturity type }\end{array}$} & 京农科 728 Jingnongke 728 & $7 / 9$ & $9 / 1$ & 107 & 54 & 1406.5 \\
\hline & 农华 101 Nonghua 101 & $7 / 10$ & $9 / 1$ & 108 & 53 & 1379.6 \\
\hline 中熟类型 & 京单 28 Jingdan 28 & $7 / 10$ & $9 / 6$ & 112 & 58 & 1488.8 \\
\hline \multirow{7}{*}{$\begin{array}{c}\text { Medium } \\
\text { maturity type }\end{array}$} & 先玉 335 Xianyu 335 & $7 / 10$ & $9 / 5$ & 112 & 57 & 1467.2 \\
\hline & NK718 & $7 / 13$ & $9 / 8$ & 113 & 57 & 1447.5 \\
\hline & 京华 8 号 Jinghua 8 & $7 / 13$ & $9 / 9$ & 114 & 58 & 1468.6 \\
\hline & 利民 33 Limin 33 & $7 / 13$ & $9 / 9$ & 114 & 58 & 1468.6 \\
\hline & 京科 528 Jingke 528 & $7 / 14$ & $9 / 8$ & 114 & 56 & 1417.1 \\
\hline & 京单 38 Jingdan 38 & $7 / 10$ & $9 / 5$ & 114 & 57 & 1467.2 \\
\hline & 京科 665 Jingke 665 & $7 / 10$ & $9 / 8$ & 116 & 60 & 1531.5 \\
\hline 中晚熟类型 & 郑单 958 Zhengdan 958 & $7 / 14$ & $9 / 16$ & 121 & 64 & 1566.2 \\
\hline $\begin{array}{l}\text { Medium-late } \\
\text { maturity type }\end{array}$ & 京科 968 Jingke 968 & $7 / 13$ & $9 / 15$ & 121 & 64 & 1577.8 \\
\hline
\end{tabular}


$107 \mathrm{~d} \pm 0.6 \mathrm{~d}$ )长 $7 \mathrm{~d}$ 和 $14 \mathrm{~d}$; 吐丝至生理成熟(灌浆期) 的天数, 中晚熟品种(平均 $64 \mathrm{~d}$ )分别较中熟品种(平 均 $58 \mathrm{~d} \pm 1.2 \mathrm{~d}$ )和中早熟品种(平均 $54 \mathrm{~d} \pm 0.6 \mathrm{~d}$ ) 长 $6 \mathrm{~d}$ 和 $10 \mathrm{~d}$; 灌浆期的积温, 中晚熟品种 (平均 $1572.0^{\circ} \mathrm{C}$ $\mathrm{d} \pm 8.0^{\circ} \mathrm{C} \mathrm{d}$ )分别较中熟品种 (平均 $1469.6^{\circ} \mathrm{C} \mathrm{d} \pm 32.6^{\circ} \mathrm{C}$ d) 和中早熟品种 (平均 $1397.5^{\circ} \mathrm{C} \quad \mathrm{d} \pm 15.5^{\circ} \mathrm{C}$ d) 多 $102.4^{\circ} \mathrm{C} \mathrm{d}$ 和 $174.5^{\circ} \mathrm{C} \mathrm{d}$ 。

\section{2 产量性状表现}

由表2可知, 穗粒数、百粒重和产量在不同熟期
类型和品种间均存在显著差异。不同熟期类型玉米 品种间, 平均产量以中晚熟品种最高 $(13,813.0 \mathrm{~kg}$ $\left.\mathrm{hm}^{-2}\right)$ 、中熟品种次之 $\left(12,970.4 \mathrm{~kg} \mathrm{hm}^{-2}\right)$ 、中早熟品种 最低 $\left(10,729.0 \mathrm{~kg} \mathrm{hm}^{-2}\right)$, 中晚熟品种平均产量分别较 中熟和中早熟品种高 $6.5 \%$ 和 $28.7 \%$, 中熟品种平均产 量较中早熟品种高 $20.9 \%$ 。不同玉米品种间，产量以 中晚熟品种京科968最高 $\left(14,813.0 \mathrm{~kg} \mathrm{hm}^{-2}\right)$, 较同熟 期类型品种郑单 958 高 $15.6 \%$; 中熟品种京科 665 和 NK718产量次之, 中早熟品种农华101产量最低。

表 2 不同熟期类型玉米品种的产量构成

Table 2 Yield components of maize hybrids with different maturity

\begin{tabular}{|c|c|c|c|c|}
\hline $\begin{array}{c}\text { 熟期类型 } \\
\text { Maturity type }\end{array}$ & $\begin{array}{c}\text { 品种 } \\
\text { Hybrid } \\
\end{array}$ & $\begin{array}{c}\text { 穗粒数 } \\
\text { Number of grains }\end{array}$ & $\begin{array}{c}\text { 百粒重 } \\
\text { 100-grain weight }(\mathrm{g})\end{array}$ & $\begin{array}{c}\text { 产量 } \\
\text { Yield }\left(\mathrm{kg} \mathrm{hm}^{-2}\right) \\
\end{array}$ \\
\hline 中早熟类型 & 吉单 27 Jidan 27 & 555 ef & $37.2 \mathrm{gh}$ & $11,062.0$ hij \\
\hline \multirow[t]{3}{*}{ Medium-early maturity type } & 京农科 728 Jingnongke 728 & $522 \mathrm{fg}$ & $38.8 \mathrm{e}$ & $10,875.5 \mathrm{ij}$ \\
\hline & 农华 101 Nonghua 101 & $607 \mathrm{~cd}$ & $35.5 \mathrm{i}$ & $10,249.5 \mathrm{j}$ \\
\hline & 平均值 Average & 561 & 37.2 & $10,729.0$ \\
\hline 中熟类型 & 京单 28 Jingdan 28 & $493 \mathrm{~g}$ & $42.3 \mathrm{~b}$ & $12,187.0$ efg \\
\hline \multirow[t]{8}{*}{ Medium maturity type } & 先玉 335 Xianyu 335 & $644 \mathrm{abc}$ & $38.4 \mathrm{ef}$ & $13,187.5 \mathrm{cde}$ \\
\hline & NK718 & $654 \mathrm{abc}$ & $36.5 \mathrm{hi}$ & $13,999.0 \mathrm{abc}$ \\
\hline & 京华 8 号 Jinghua 8 & $531 \mathrm{fg}$ & $40.9 \mathrm{c}$ & $12,000.5 \mathrm{fgh}$ \\
\hline & 利民 33 Limin 33 & $686 \mathrm{a}$ & $32.5 \mathrm{j}$ & 11,714.5 ghi \\
\hline & 京科 528 Jingke 528 & $570 \mathrm{def}$ & $44.1 \mathrm{a}$ & $13,750.0 \mathrm{bcd}$ \\
\hline & 京单 38 Jingdan 38 & $605 \mathrm{cde}$ & $39.1 \mathrm{de}$ & $12,625.5 \mathrm{efg}$ \\
\hline & 京科 665 Jingke 665 & $677 \mathrm{ab}$ & $37.3 \mathrm{gh}$ & $14,299.5 \mathrm{ab}$ \\
\hline & 平均值 Average & 608 & 38.9 & $12,970.4$ \\
\hline \multirow{3}{*}{$\begin{array}{c}\text { 中晚熟类型 } \\
\text { Medium-late maturity type }\end{array}$} & 郑单 958 Zhengdan 958 & $628 \mathrm{bc}$ & $37.6 \mathrm{fg}$ & $12,813.0 \mathrm{def}$ \\
\hline & 京科 968 Jingke 968 & $675 \mathrm{ab}$ & $40.1 \mathrm{~cd}$ & $14,813.0 \mathrm{a}$ \\
\hline & 平均值 Average & 652 & 38.9 & $13,813.0$ \\
\hline 变异来源 & 熟期类型 Maturity type & ** & ** & ** \\
\hline Source of variation & 品种 Hybrid & ** & ** & ** \\
\hline
\end{tabular}

同一列数字后不同小写字母表示不同处理间差异达 0.05 显著水平。 ${ }^{* *}$ 表示在 $P<0.01$ 水平差异显著。

Values followed by different lowercase letters within a column are significantly different at the 0.05 probability level among different treatments. ${ }^{* *}$ indicates significant differences at $P<0.01$.

\section{3 籽粒灌浆参数}

由表 3 可知, 活跃灌浆期积温 $(P)$ 、平均和最大 灌浆速率 $\left(G_{\mathrm{ave}}\right.$ 和 $\left.G_{\mathrm{max}}\right)$ 在不同熟期类型和玉米品种 间均存在显著差异。不同熟期类型间, 以中晚熟品 种的 $G_{\max }$ 和 $G_{\mathrm{ave}}$ 最低(分别为 $0.040 \mathrm{~g} 100$-grain ${ }^{-1}{ }^{\circ} \mathrm{C}^{-1}$ 和 $0.027 \mathrm{~g} 100$-grain $\left.{ }^{-1}{ }^{\circ} \mathrm{C}^{-1}\right) 、 P\left(1383.95^{\circ} \mathrm{C}\right)$ 最多; 中 熟品种 $P\left(1230.37^{\circ} \mathrm{C}\right) 、 G_{\max }$ 和 $G_{\text {ave }}$ (分别为 $0.045 \mathrm{~g}$ 100 -grain ${ }^{-1}{ }^{\circ} \mathrm{C}^{-1}$ 和 $0.031 \mathrm{~g} 100$-grain $\left.{ }^{-1}{ }^{\circ} \mathrm{C}^{-1}\right)$ 居中; 中 早熟品种 $P\left(1049.52^{\circ} \mathrm{C}\right)$ 最少, $G_{\max }$ 和 $G_{\mathrm{ave}}$ 最高(分别 为 $0.050 \mathrm{~g} 100$-grain ${ }^{-1}{ }^{\circ} \mathrm{C}^{-1}$ 和 $0.034 \mathrm{~g} \mathrm{100- \text {grain } ^ { - 1 }}$ ${ }^{\circ} \mathrm{C}^{-1}$ )。
相同熟期类型不同品种间的籽粒灌浆参数也 存在较大差异。中早熟类型品种中, 京农科 728 和吉单 27 的 $G_{\mathrm{ave}}$ 和 $G_{\max }$ 相当且均显著高于农华 101, 但 3 个品种的活跃灌浆期积温差异显著。中 熟类型品种中, 京华 8 号的 $G_{\mathrm{ave}}$ 和 $G_{\mathrm{max}}$ 均显著高 于其他品种, 但活跃灌浆期积温最少; 京单 28 、京 科 528 和京单 38 , 以及先玉 335 和 NK718 的 $G_{\text {ave }}$ 和 $G_{\max }$ 均分别相当, 但活跃灌浆期积温差异显著。 中晚熟类型品种京科 968 的 $G_{\mathrm{ave}}$ 和 $G_{\mathrm{max}}$ 均显著高 于郑单 958 , 但活跃灌浆期积温表现为郑单 958 高 于京科 968 。 
表 3 不同熟期类型玉米品种的灌浆特征参数

Table 3 Parameters of grain-filling characteristics of maize hybrids with different maturity

\begin{tabular}{|c|c|c|c|c|}
\hline $\begin{array}{c}\text { 熟期类型 } \\
\text { Maturity type }\end{array}$ & $\begin{array}{c}\text { 品种 } \\
\text { Hybrid } \\
\end{array}$ & $\begin{array}{c}\text { 活跃灌浆期积温 } \\
P\left({ }^{\circ} \mathrm{C}\right) \\
\end{array}$ & $\begin{array}{c}\text { 平均灌浆速率 } \\
G_{\text {ave }}\left(\text { g } 100 \text {-grain }{ }^{-1}{ }^{\circ} \mathrm{C}^{-1}\right)\end{array}$ & $\begin{array}{c}\text { 最大灌浆速率 } \\
G_{\max }\left(\mathrm{g} 100 \text { - } \text { grain }^{-1}{ }^{\circ} \mathrm{C}^{-1}\right) \\
\end{array}$ \\
\hline \multirow{4}{*}{$\begin{array}{c}\text { 中早熟类型 } \\
\text { Medium-early maturity } \\
\text { type }\end{array}$} & 吉单 27 Jidan 27 & $967.12 \mathrm{k}$ & $0.036 \mathrm{a}$ & $0.053 \mathrm{~b}$ \\
\hline & 京农科 728 Jingnongke 728 & $1001.41 \mathrm{j}$ & $0.036 \mathrm{a}$ & $0.054 \mathrm{ab}$ \\
\hline & 农华 101 Nonghua 101 & $1180.04 \mathrm{~h}$ & $0.028 \mathrm{c}$ & $0.042 \mathrm{~d}$ \\
\hline & 平均值 Average & 1049.52 & 0.034 & 0.050 \\
\hline \multirow{9}{*}{$\begin{array}{c}\text { 中熟类型 } \\
\text { Medium maturity type }\end{array}$} & 京单 28 Jingdan 28 & $1191.59 \mathrm{~g}$ & $0.033 \mathrm{~b}$ & $0.049 \mathrm{c}$ \\
\hline & 先玉 335 Xianyu 335 & $1343.93 \mathrm{~b}$ & $0.028 \mathrm{c}$ & $0.042 \mathrm{~d}$ \\
\hline & NK718 & $1258.63 \mathrm{e}$ & $0.028 \mathrm{c}$ & $0.041 \mathrm{~d}$ \\
\hline & 京华 8 号 Jinghua 8 & $1009.70 \mathrm{i}$ & $0.038 \mathrm{a}$ & $0.056 \mathrm{a}$ \\
\hline & 利民 33 Limin 33 & $1260.09 \mathrm{e}$ & $0.025 \mathrm{~d}$ & $0.037 \mathrm{f}$ \\
\hline & 京科 528 Jingke 528 & $1290.57 \mathrm{c}$ & $0.032 \mathrm{~b}$ & $0.048 \mathrm{c}$ \\
\hline & 京单 38 Jingdan 38 & $1218.27 \mathrm{f}$ & $0.033 \mathrm{~b}$ & $0.048 \mathrm{c}$ \\
\hline & 京科 665 Jingke 665 & $1270.15 \mathrm{~d}$ & $0.027 \mathrm{~cd}$ & $0.040 \mathrm{de}$ \\
\hline & 平均值 Average & 1230.37 & 0.031 & 0.045 \\
\hline \multirow{3}{*}{$\begin{array}{c}\text { 中晚熟类型 } \\
\text { Medium-late maturity } \\
\text { type }\end{array}$} & 郑单 958 Zhengdan 958 & $1423.28 \mathrm{a}$ & $0.026 \mathrm{~d}$ & 0.038 ef \\
\hline & 京科 968 Jingke 968 & $1344.61 \mathrm{~b}$ & $0.028 \mathrm{c}$ & $0.042 \mathrm{~d}$ \\
\hline & 平均值 Average & 1383.95 & 0.027 & 0.040 \\
\hline \multirow{2}{*}{$\begin{array}{c}\text { 变异来源 } \\
\text { Source of variation }\end{array}$} & 熟期类型 Maturity type & $* *$ & $* *$ & $* *$ \\
\hline & 品种 Hybrid & $* *$ & $* *$ & $* *$ \\
\hline
\end{tabular}

$P:$ 活跃灌浆期积温; $G_{\text {ave: }}$ 平均灌浆速率; $G_{\max }$ : 最大灌浆速率。同一列数字后不同小写字母表示不同处理间差异达 0.05 显著水平。 $* *$ 表示在 $P<0.01$ 水平差异显著。

$P$ : accumulated temperature during active grain filling stage; $G_{\text {ave }}$ : average grain-filling rate; $G_{\max }$ : maximum grain-filling rate. Values followed by different lowercase letters within a column are significantly different at the 0.05 probability level among different treatments. ** indicates significant differences at $P<0.01$.

\section{4 籽粒含水率和脱水速率}

不同熟期类型和不同品种生理成熟期和收获期 的籽粒含水率均存在显著差异(表4)。不同熟期类型 间，籽粒生理成熟期平均含水率表现为中熟品种 (31.0\%)>中晚熟品种 $(29.8 \%)>$ 中早熟品种 $(28.9 \%)$; 收获期平均籽粒含水率则总体表现为随着熟期延长 䊏粒含水率呈增加趋势, 具体为中晚熟品种 (24.7\%)>中熟品种 $(23.0 \%)>$ 中早熟品种 $(21.2 \%)$ 。不 同品种间, 生理成熟期籽粒含水率变幅为 $26.6 \%$ (吉 单 27) 32.4\% (利民 33), 其中含水率 32\%以上品种 2 个(京单 $28<$ 利民 33 )、30\%以下品种 4 个(吉单 $27<$ 京科 $665<$ 京科 $968<$ 农华 101)，其余品种介于 $30.0 \%$ $32.0 \%$; 收获期籽粒含水率以京农科 728 (19.8\%)最 低、郑单 $958(25.5 \%)$ 最高，其余品种介于 $20.9 \%$ $24.0 \%$ 。

不同熟期类型和不同品种生理成熟前的生理降 水速率、生理成熟后的物理脱水速率及总脱水速率
均存在显著差异(表 4)。不同熟期类型间, 生理成熟 前的生理降水速率和平均总脱水速率表现为中早熟 品种 $\left[0.044 \%\left({ }^{\circ} \mathrm{C} \mathrm{d}\right)^{-1}\right.$ 和 $\left.0.035 \%\left({ }^{\circ} \mathrm{C} \mathrm{d}\right)^{-1}\right]>$ 中熟品种 $\left[0.040 \%\left({ }^{\circ} \mathrm{C} \mathrm{d}\right)^{-1}\right.$ 和 $\left.0.034 \%\left({ }^{\circ} \mathrm{C} \mathrm{d}\right)^{-1}\right]>$ 中晚熟品种 $\left[0.038 \%\left({ }^{\circ} \mathrm{C} \mathrm{d}\right)^{-1}\right.$ 和 $\left.0.028 \%\left({ }^{\circ} \mathrm{C} \mathrm{d}\right)^{-1}\right]$, 生理成熟后的 物理脱水速率则表现为中熟品种 $\left[0.027 \%\left({ }^{\circ} \mathrm{C} d\right)^{-1}\right]>$ 中早熟品种 $\left[0.025 \%\left({ }^{\circ} \mathrm{C} d\right)^{-1}\right]>$ 中晚熟品种 $[0.018 \%$ $\left.\left({ }^{\circ} \mathrm{C} \mathrm{d}\right)^{-1}\right]$ 。不同品种间, 生理降水速率变幅为 $0.038 \%$ $\left({ }^{\circ} \mathrm{C} \mathrm{d}\right)^{-1}$ (郑单 958 和京科 968 ) $0.045 \%\left({ }^{\circ} \mathrm{C} \mathrm{d}\right)^{-1}$ (吉单 27 ), 物理脱水速率变幅为 $0.012 \%\left({ }^{\circ} \mathrm{C} \mathrm{d}\right)^{-1}$ (吉单 27) $0.034 \%\left({ }^{\circ} \mathrm{C} \mathrm{d}\right)^{-1}$ (京农科 728), 平均总脱水速率 变幅为 $0.027 \%\left({ }^{\circ} \mathrm{C} \mathrm{d}\right)^{-1}$ (郑单 958) 0.038\% $\left({ }^{\circ} \mathrm{C} \mathrm{d}\right)^{-1}$ (京农科 728)。进一步分析发现, 生理成熟期及收获 期的籽粒含水率、生理降水速率、物理脱水速率及总平 均脱水速率的变异系数分别为 $5.07 \% 、 6.41 \% 、 5.35 \%$ 、 $30.11 \%$ 和 $11.86 \%$ 。这说明，参试玉米品种生理成熟后的 物理脱水速率较其他指标存在更大的差异。 
表 4 不同熟期类型玉米品种的籽粒含水率和脱水速率

Table 4 Grain moisture content and dehydrating rate of maize hybrids with different maturity

\begin{tabular}{|c|c|c|c|c|c|c|}
\hline \multirow{2}{*}{$\begin{array}{c}\text { 熟期类型 } \\
\text { Maturity type }\end{array}$} & \multirow{2}{*}{$\begin{array}{l}\text { 品种 } \\
\text { Hybrid }\end{array}$} & \multicolumn{2}{|c|}{$\begin{array}{c}\text { 籽粒含水率 } \\
\text { Grain moisture content (\%) }\end{array}$} & \multirow{2}{*}{$\begin{array}{c}\text { 生理成熟前平均生理 } \\
\text { 降水速率 } \\
\text { Physiological } \\
\text { dehydration rate before } \\
\text { physiological } \\
\text { maturity }\left[\%\left({ }^{\circ} \mathrm{C} d\right)^{-1}\right]\end{array}$} & \multirow{2}{*}{$\begin{array}{c}\text { 生理成熟后平均 } \\
\text { 物理脱水速率 } \\
\text { Physical dehydration } \\
\text { rate after physiological } \\
\text { maturity }\left[\%\left({ }^{\circ} \mathrm{C}\right.\right. \\
\left.\text { d })^{-1}\right]\end{array}$} & \multirow{2}{*}{$\begin{array}{c}\text { 平均总脱水速率 } \\
\text { Average total de- } \\
\text { hydration } \\
\text { rate }\left[\%\left({ }^{\circ} \mathrm{C} \mathrm{d}\right)^{-1}\right]\end{array}$} \\
\hline & & $\begin{array}{c}\text { 生理成熟期 } \\
\text { Physiological } \\
\text { maturity }\end{array}$ & $\begin{array}{c}\text { 收获期 } \\
\text { Harvest stage }\end{array}$ & & & \\
\hline \multirow{4}{*}{$\begin{array}{l}\text { 中早熟类型 } \\
\text { Medium-early } \\
\text { maturity type }\end{array}$} & 吉单 27 Jidan 27 & $26.6 \mathrm{e}$ & $23.0 \mathrm{bcd}$ & $0.045 \mathrm{a}$ & $0.012 \mathrm{f}$ & $0.028 \mathrm{~cd}$ \\
\hline & $\begin{array}{l}\text { 京农科 } 728 \\
\text { Jingnongke } 728\end{array}$ & $30.2 \mathrm{abcd}$ & $19.8 \mathrm{f}$ & $0.043 \mathrm{ab}$ & $0.034 \mathrm{a}$ & $0.038 \mathrm{a}$ \\
\hline & 农华 101 Nonghua 101 & $29.9 \mathrm{bcd}$ & $20.9 \mathrm{e}$ & $0.044 \mathrm{a}$ & $0.030 \mathrm{~b}$ & $0.037 \mathrm{a}$ \\
\hline & 平均值 Average & 28.9 & 21.2 & 0.044 & 0.025 & 0.035 \\
\hline \multirow{9}{*}{$\begin{array}{c}\text { 中熟类型 } \\
\text { Medium } \\
\text { maturity type }\end{array}$} & 京单 28 Jingdan 28 & $32.2 \mathrm{ab}$ & $22.3 \mathrm{~cd}$ & $0.039 \mathrm{c}$ & $0.033 \mathrm{ab}$ & $0.036 \mathrm{a}$ \\
\hline & 先玉 335 Xianyu 335 & $30.2 \mathrm{abcd}$ & $23.8 \mathrm{~b}$ & $0.041 \mathrm{bc}$ & $0.022 \mathrm{~cd}$ & $0.031 \mathrm{bc}$ \\
\hline & NK718 & $30.2 \mathrm{abcd}$ & $23.2 \mathrm{bc}$ & $0.041 \mathrm{bc}$ & $0.024 \mathrm{c}$ & $0.032 \mathrm{~b}$ \\
\hline & 京华 8 号 Jinghua 8 & $31.6 \mathrm{abc}$ & $22.1 \mathrm{~d}$ & $0.040 \mathrm{bc}$ & $0.032 \mathrm{ab}$ & $0.036 \mathrm{a}$ \\
\hline & 利民 33 Limin 33 & $32.4 \mathrm{a}$ & $22.4 \mathrm{~cd}$ & $0.039 \mathrm{c}$ & $0.034 \mathrm{ab}$ & $0.037 \mathrm{a}$ \\
\hline & 京科 528 Jingke 528 & $31.9 \mathrm{abc}$ & $22.6 \mathrm{~cd}$ & $0.041 \mathrm{bc}$ & $0.032 \mathrm{ab}$ & $0.036 \mathrm{a}$ \\
\hline & 京单 38 Jingdan 38 & $30.7 \mathrm{abcd}$ & $23.9 \mathrm{~b}$ & $0.040 \mathrm{bc}$ & $0.023 \mathrm{~cd}$ & $0.032 \mathrm{~b}$ \\
\hline & 京科 665 Jingke 665 & $29.1 \mathrm{~d}$ & $23.9 \mathrm{~b}$ & $0.040 \mathrm{bc}$ & $0.018 \mathrm{e}$ & $0.029 \mathrm{c}$ \\
\hline & 平均值 Average & 31.0 & 23.0 & $0.040 \mathrm{bc}$ & 0.027 & 0.034 \\
\hline \multirow{4}{*}{$\begin{array}{l}\text { 中晚熟类型 } \\
\text { Medium-late } \\
\text { maturity type }\end{array}$} & 郑单 958 & $30.0 \mathrm{abcd}$ & $25.5 \mathrm{a}$ & $0.038 \mathrm{c}$ & 0.016 ef & $0.027 \mathrm{~d}$ \\
\hline & Zhengdan 958 & & & & & \\
\hline & 京科 968 Jingke 968 & $29.5 \mathrm{~cd}$ & $24.0 \mathrm{~b}$ & $0.038 \mathrm{c}$ & $0.019 \mathrm{~d}$ & $0.029 \mathrm{c}$ \\
\hline & 平均值 Average & 29.8 & 24.7 & 0.038 & 0.018 & 0.028 \\
\hline $\begin{array}{l}\text { 变异来源 } \\
\text { Source of }\end{array}$ & $\begin{array}{l}\text { 熟期类型 } \\
\text { Maturity type }\end{array}$ & $* *$ & $* *$ & $* *$ & $* *$ & $* *$ \\
\hline variation & 品种 Hybrid & $* *$ & $* *$ & $* *$ & $* *$ & $* *$ \\
\hline
\end{tabular}

同一列数字后不同小写字母表示不同处理间差异达 0.05 显著水平。 $* *$ 表示在 $P<0.01$ 水平差异显著。

Values within a column followed by different lowercase letters are significantly different at the 0.05 probability level among different treatments. ** indicates significant differences at $P<0.01$.

\section{5 籽粒灌浆脱水及产量参数相关分析}

对籽粒灌浆、脱水及产量相关参数进行相关分 析(表5)表明, 产量与吐丝至生理成熟天数及相应 积温极显著正相关，与活跃灌浆期积温、平均灌浆 速率和收获期百粒干物重显著正相关, 收获期百 粒干物重与活跃灌浆期积温、平均灌浆速率和产量 显著正相关, 这说明灌浆期越长、灌浆速率越高, 粒重越大、产量越高; 生理成熟期籽粒含水率与生 理成熟前籽粒平均生理降水速率没有显著相关性, 但与生理成熟后籽粒平均物理脱水速率和总脱水 速率极显著正相关, 说明生理成熟期籽粒含水率 越高后期脱水越快; 收获期籽粒含水率与吐丝至 生理成熟天数及相应积温、活跃灌浆期积温极显著 正相关, 与生理成熟前平均生理降水速率、生理成
熟后平均物理脱水速率及总平均脱水速率极显著 负相关, 说明灌浆期越长收获期籽粒含水率越高、 脱水越快收获期籽粒含水率越低; 生理成熟前籽 粒平均生理降水速率与吐丝一生理成熟天数及相 应积温、活跃灌浆期积温极显著负相关，说明灌浆 期越短, 生理成熟前籽粒平均生理降水速度越快; 生理成熟后的籽粒平均脱水降水速率与生理成熟 期籽粒含水率极显著正相关、与收获期籽粒含水 率极显著负相关, 说明生理成熟期籽粒含水率越 高则生理成熟后的籽粒物理脱水速度越快, 物理 脱水速度越快则收获期籽粒含水率越低; 生理成 熟前平均生理降水速率、生理成熟后平均物理脱 水速率及平均总脱水速率与平均灌浆速率相关性 不显著。 


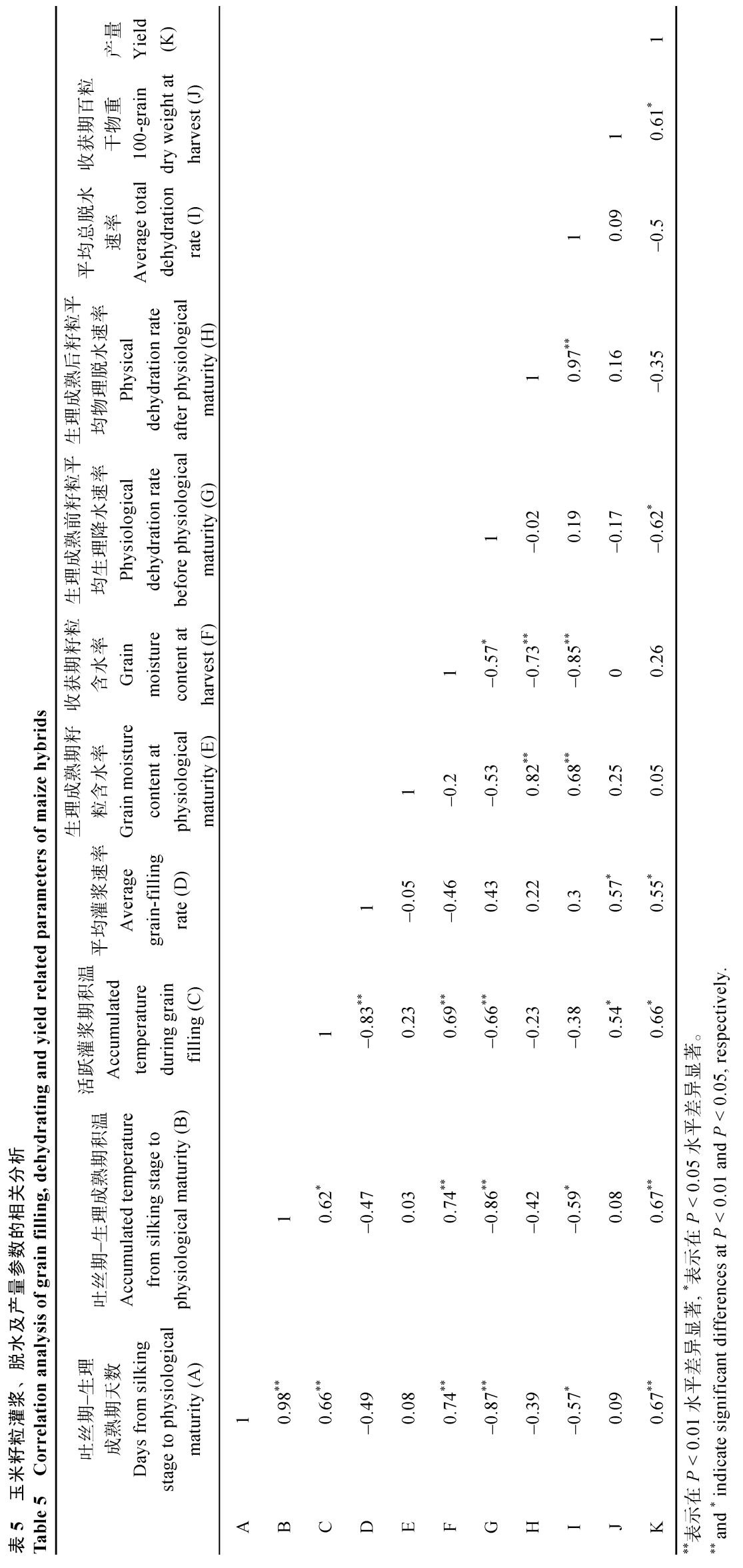




\section{3 讨论}

为实现不同熟期玉米品种籽粒灌浆和脱水特性 的可比性, 本文参照李璐璐等 ${ }^{[1]}$ 方法, 以积温作为 玉米生育进程的估算指标, 以避免不同熟期品种因 籽粒灌浆和脱水处于不同环境特别是温度条件下而 无法客观评价籽粒灌浆和脱水速率。

玉米籽粒灌浆过程主要通过灌浆时间和灌浆速 率共同影响粒重和产量 ${ }^{[10-11]}$ 。金益等 ${ }^{[19]}$ 研究发现, 早熟和晚熟高产玉米粒重和产量的差异主要由灌浆 时间决定。本研究表明, 产量与灌浆期天数、积温、 平均灌浆速率和粒重呈极显著或显著正相关，粒重 与活跃灌浆期积温、平均灌浆速率和产量显著正相 关, 这说明灌浆期越长、灌浆速率越高, 粒重越大、 产量越高, 与前人研究结果一致。进一步分析发现, 灌浆进程不同是导致不同熟期品种籽粒灌浆速率差 异显著的主要原因。本研究结果表明, 从籽粒灌浆 特性和产量水平来看, 不同熟期品种的灌浆速率以 生育期相对较短的中早熟品种为最高, 但因活跃灌 浆期最短, 干物质积累有限, 因此粒重和产量最低; 中晚熟品种虽然灌浆速率最低, 但活跃灌浆期最长, 有利于干物质积累和获得较高粒重, 再加上穗粒数 较多, 因此产量潜力最大, 分别较中熟和中早熟品 种高 $6.5 \%$ 和 $28.7 \%$; 中熟品种则协调了高产和早熟 的矛盾, 虽然熟期较中晚熟品种早, 但灌浆持续期 长, 灌浆强度大, 平均粒重与中晚熟品种相当(百粒 千物重 $38.9 \mathrm{~g}$ ), 且具有较高的产量潜力, 较中早熟 品种高 $20.9 \%$ 。

玉米籽粒生理成熟前的生理降水速率和生理成 熟后的物理脱水速率直接影响籽粒生理成熟期和收 获期的含水率 ${ }^{[12]}$ 。李凤海等 ${ }^{[15]}$ 研究表明, 熟期对籽 粒脱水速率有明显影响, 不同熟期玉米品种的籽粒 脱水速率差异显著, 中晚熟品种高于晚熟品种。分 析本研究不同熟期玉米品种的籽粒脱水特性, 结果 表明中早熟品种生理成熟前的平均生理降水速率最 高, 且生理成熟后仍可保持较高的物理脱水速率, 因此生理成熟期和收获期籽粒含水率均最低; 中晚 熟品种生理降水速率及物理脱水速率最低, 导致生 理成熟期和收获期的䊏粒平均含水率 $(29.8 \%$ 和 $24.7 \%$ )较高; 中熟品种的生理降水速率相对较高, 但灌浆期相对较短, 生理成熟期籽粒含水率高, 但 生理成熟后仍可保持较高的物理脱水速率, 因此收 获期籽粒含水率低于中晚熟品种。关于不同熟期玉
米品种生理成熟时的籽粒含水率, Afuakwa等 ${ }^{[20]}$ 认 为晚熟品种高于早熟品种, 赵淑杰等 ${ }^{[21]}$ 认为晚熟组 合高于早熟和中熟组合, 万泽花等 ${ }^{[17]}$ 则认为早熟玉 米品种未必低于晚熟品种。本研究表明, 生理成熟 时的籽粒含水率中晚熟品种 (平均 $29.8 \%$ ) 高于中早 熟品种(平均 $28.9 \%$ ), 这与前人研究结果一致, 并且 中熟品种虽然熟期早于中晚熟品种但生理成熟时籽 粒含水率(平均 $31.0 \%$ )为 3 个类型中最高。这说明, 虽 然熟期是影响籽粒脱水的重要因素, 但生理成熟时 的籽粒含水率与品种熟期没有严格对应关系，本文 相关分析也证实了该观点。

玉米籽粒的灌浆和脱水进程、收获时的成熟度 和含水率与气候条件密切相关 ${ }^{[22-24]}$, 充分协调玉米 品种熟期、籽粒灌浆及脱水的关系，对指导玉米生 产品种布局、挖掘品种高产潜力和实现高产优质具 有重要意义。本研究相关分析表明, 平均生理降水 速率、物理脱水速率及总脱水速率与平均灌浆速率 相关性不显著, 这与万泽花等 ${ }^{[16]}$ 和李璐璐等 ${ }^{[1]}$ 的研 究结果一致。此外, 本研究还表明即使相同熟期品 种其籽粒灌浆和脱水特性也存在较大差异。如, 中 早熟代表性品种京农科 728 的平均灌浆速率和生理 成熟后的物理脱水速率分别较 3 个熟期代表性品种 郑单 958、先玉 335 、农华 101 高 38.5\%和 $112.5 \%$ 、 $28.6 \%$ 和 $54.5 \%$ 、28.6\%和 $13.3 \%$; 中晚熟代表性品 种京科 968 产量潜力最大 $\left(14,813.0 \mathrm{~kg} \mathrm{hm}^{-2}\right)$, 且平 均灌浆速率和物理脱水速率分别较同熟期品种郑 单 958 高 $7.7 \%$ 和 $18.8 \%$ 。前人研究也得到类似结论, 如赵淑杰等 ${ }^{[21]}$ 研究表明同一熟期玉米组合的脱水 速率存在显著差异, 谭福忠等 ${ }^{[25]}$ 研究表明 5 个极早 熟玉米品种间生理成熟时的籽粒含水率差异显著、 收获时的籽粒含水率差异极显著。分析其原因, 除 熟期外, 还应与不同品种的籽粒内部结构与化学成 分以及叶片、茎秆、穗部等的脱水速率密切相关 ${ }^{[26-31]}$ 。 因此, 为实现玉米高产优质和资源高效利用, 生产 中品种布局应充分考虑品种的熟期及其籽粒灌浆 和脱水特性。

\section{4 结论}

不同熟期类型和玉米品种的产量、籽粒灌浆和 脱水特性均存在显著差异。中晚熟品种产量最高, 分别较中早熟和中熟品种高 $28.7 \%$ 和 $6.5 \%$, 平均灌 浆速率表现为中早熟>中熟>中晚熟品种, 生理成熟 后的平均物理脱水速率表现为中熟 $>$ 中早熟 $>$ 中晚熟 
品种，且同一熟期不同品种的籽粒灌浆和脱水特性 也存在较大差异。玉米生产中合理品种布局除需考 虑品种熟期外, 还应兼顾其籽粒灌浆和脱水特性。 热量资源不足地区宜选择生育期和灌浆期短、灌浆 和脱水快的中早熟品种, 热量资源紧张地区宜选择 产量潜力较大、灌浆及生理成熟后脱水快的中熟品 种，热量资源充足地区则宜选择生育期和灌浆期 长、产量潜力大的中晚熟品种。

\section{References}

[1] 李璐璐, 明博, 高尚, 谢瑞芝, 侯鹏, 王克如, 李少昆. 夏玉米 籽粒脱水特性及与灌浆特性的关系. 中国农业科学, 2018, 51: 1878-1889.

Li L L, Ming B, Gao S, Xie R Z, Hou P, Wang K R, Li S K. Study on grain dehydration characters of summer maize and its relationship with grain filling. Sci Agric Sin, 2018, 51: 1878-1889 (in Chinese with English abstract).

[2] 谢瑞芝, 雷晓鹏, 王克如, 郭银巧, 柴宗文, 侯鹏, 李少昆. 黄 淮海夏玉米子粒机械收获研究初报. 作物杂志, 2014, (2): 76-79.

Xie R Z, Lei X P, Wang K R, Guo Y Q, Chai Z W, Hou P, Li S K. Research on corn mechanically harvesting grain quality in Huanghuaihai plain. Crops, 2014, (2): 76-79 (in Chinese with English abstract).

[3] 王志红, 周福民, 郭华, 王静, 靳海蕾, 刘海霞, 王良发, 申亚 飞, 杨美丽, 王帮太. 玉米籽粒脱水速率研究分析及种质改良 策略. 农学学报, 2015, 5(7): 15-18.

Wang Z H, Zhou F M, Guo H, Wang J, Jin H L, Liu H X, Wang L F, Shen Y F, Yang M L, Wang B T. Research and analysis on dehydration rate of maize grain and germplasm improvement tactics. J Agric, 2015, 5(7): 15-18 (in Chinese with English abstract).

[4] 张海艳, 董树亭, 高荣岐. 不同类型玉米子粒灌浆特性分析. 玉米科学, 2007, 15(3): 67-70.

Zhang H Y, Dong S T, Gao R Q. Analysis on kernel filling characteristics for different maize types. J Maize Sci, 2007, 15(3): 67-70 (in Chinese with English abstract).

[5] 李绍长, 周锦瑶, 盛茜. 五种基因型玉米子粒灌浆特性的研究. 石河子大学学报, 1997, (1): 190-193.

Li S Z, Zhou J Y, Sheng Q. Studies on the trait of grain filling in five genotypes maize kernel. J Shihezi Univ, 1997, (1): 190-193 (in Chinese with English abstract).

[6] Cross H Z. Leaf expansion rate effects on yield and yield components in early-maturing maize. Crop Sci, 1991, 31: 579-583.

[7] Magari R, Kang M S, Zhang Y. Sample size for evaluating field ear moisture loss rate in maize. Maydica, 1996, 41: 19-24.

[8] 于宁宁, 任佰朝, 赵斌, 刘鹏, 张吉旺. 施氮量对夏玉米籽粒 灌浆特性和营养品质的影响。应用生态学报，2019，30: 3771-3776.

Yu N N, Ren B Z, Zhao B, Liu P, Zhang J W. Effects of nitrogen application rate on grain filling characteristics and nutritional quality of summer maize. $J$ Appl Ecol, 2019, 30: 3771-3776 (in Chinese with English abstract).

[9] 冯鹏, 申晓慧, 郑海燕, 张华, 李增杰, 杨海宽, 李明顺. 种植
密度对玉米籽粒灌浆及脱水特性的影响. 中国农学通报, 2014, 30(6): 92-100.

Feng P, Shen X H, Zheng H Y, Zhang H, Li Z J, Yang H K, Li M $\mathrm{S}$. Effects of nitrogen application rate on grain filling characteristics and nutritional quality of summer maize. Chin Agric Sci Bull, 2014, 30(6): 92-100 (in Chinese with English abstract).

[10] 马冲, 刍仁峰, 苏波, 张健, 陈举林. 不同熟期玉米籽粒灌浆 特性的研究. 作物研究, 2000, (4): 17-19.

Ma C, Zou R F, Su B, Zhang J, Chen J L. Studies on grain filling characteristics of hybrid corn with different growth durations. Crop Res, 2000, (4): 17-19 (in Chinese with English abstract).

[11] 王晓慧, 张否, 刘双利, 曹玉军, 魏雯雯, 刘春光, 王永军, 边 少锋, 王立春. 不同熟期春玉米品种的籽粒灌浆特性. 中国农 业科学, 2014, 47: 3557-3565.

Wang X H, Zhang L, Liu S L, Cao Y J, Wei W W, Liu C G, Wang Y J, Bian S F, Wang L C. Grain filling characteristics of maize hybrids differing in maturities. Sci Agric Sin, 2014, 47: 3557-3565 (in Chinese with English abstract).

[12] 王克如, 李少昆. 玉米籽粒脱水速率影响因素分析. 中国农业 科学, 2017, 50: 2027-2035.

Wang K R, Li S K. Analysis of influencing factors on kernel dehydration rate of maize hybrids. Sci Agric Sin, 2017, 50: 2027-2035 (in Chinese with English abstract).

[13] 王同朝, 卫丽, 马超, 杜园园, 常晓, 邵扬. 不同生态区夏玉 米两类熟期品种子粒灌浆动态和产量分析. 玉米科学, 2010, 18(3): 84-89.

Wang T C, Wei L, Ma C, Du Y Y, Chang X, Shao Y. Dynamic process of grain-filling and yield factors analysis of late-matured and middle-matured varieties of summer maize after flowering. $J$ Maize Sci, 2010, 18(3): 84-89 (in Chinese with English abstract).

[14] 钱春荣, 王荣焕, 赵久然, 于洋, 郝玉波, 徐田军, 姜宇博, 宫 秀杰, 李梁, 葛选良. 不同熟期玉米品种的籽粒灌浆特性及其 与温度关系研究. 中国农业科技导报, 2017, 19(8): 105-114.

Qian C R, Wang R H, Zhao J R, Yu Y, Hao Y B, Xu T J, Jiang Y B, Gong X J, Li L, Ge X L. Study on the grain filling characteristics and their relationship with temperature of maize hybrids differing in maturities. J Agric Sin Technol, 2017, 19(8): 105-114 (in Chinese with English abstract).

[15] 李凤海, 郭佳丽, 于涛, 史振声. 不同熟期玉米杂交种及其亲 本子粒脱水速率的比较研究. 玉米科学, 2012, 20(6): 17-20.

Li F H, Guo J L, Yu T, Shi Z S. Comparative study on dehydration rate of kernel among maize hybrids and parents with different maturity periods. J Maize Sci, 2012, 20(6): 17-20 (in Chinese with English abstract).

[16] 万泽花, 任佰朝, 赵斌, 刘鹏, 董树亭, 张吉旺. 不同熟期夏 玉米品种籽粒灌浆与脱水特性及其密度效应. 作物学报, 2018, 44: 1517-1526.

Wan Z H, Ren B Z, Zhao B, Liu P, Dong S T, Zhang J W. Grain filling and dehydration characteristics of summer maize hybrids differing in maturities and effect of plant density. Acta Agron Sin, 2018, 44: 1517-1526 (in Chinese with English abstract).

[17] 万泽花, 任佰朝, 赵斌, 刘鹏, 张吉旺. 不同熟期夏玉米品种 籽粒灌浆脱水特性和激素含量变化. 作物学报, 2019, 45: 1446-1453.

Wan Z H, Ren B Z, Zhao B, Liu P, Zhang J W. Grain filling, dehydration characteristics and changes of endogenous hormones of 
summer maize hybrids differing in maturities. Acta Agron Sin, 2019, 45: 1446-1453 (in Chinese with English abstract).

[18] 朱庆森, 曹显祖, 骆亦其. 水稻籽粒灌浆的生长分析. 作物学 报, 1988, 14: 182-193.

Zhu Q S, Cao X Z, Luo Y Q. Growth analysis on the process of grain filling in rice. Acta Agron Sin, 1988, 14: 182-193 (in Chinese with English abstract).

[19] 金益, 张永林, 王振华, 孙朝杰. 玉米灌浆后期百粒重变化的 品种间差异分析. 东北农业大学学报, 1998, 29(1): 7-10.

Jin Y, Zhang Y L, Wang Z H, Sun C J. Difference analysis on 100-kernel weight in 30-60 days after silking in maize hybrids. $J$ Northeast Agric Univ, 1998, 29(1): 7-10 (in Chinese with English abstract).

[20] Afuakwa J J, Crookston R K, Jones R J. Effect of temperature and sucrose availability on kernel black layer development in maize. Crop Sci, 1984, 24: 285-288.

[21] 赵淑杰, 吴华民. 玉米子粒自然脱水速率的分析. 吉林农业科 学, 2002, 27(5): 24-26.

Zhao S J, Wu H M. Analysis of kernel naturally dry-down rate corn hybrids. J Jilin Agric Sci, 2002, 27(5): 24-26 (in Chinese with English abstract).

[22] 白彩云, 李少昆, 柏军华, 张厚宝, 谢瑞芝. 我国东北地区不 同生态条件下玉米品种积温需求及利用特性. 应用生态学报, 2011, 22: 2337-2342.

Bai C Y, Li S K, Bai J H, Zhang H B, Xie R Z. Characteristics of accumulated temperature demand and its utilization of maize under different ecological conditions in northeast China. $J$ Appl Ecol, 2011, 22: 2337-2342 (in Chinese with English abstract).

[23] 戴明宏, 赵久然, 杨国航, 王荣焕, 陈国平. 不同生态区和不 同品种玉米的源库关系及碳氮代谢. 中国农业科学, 2011, 44: 1585-1595.

Dai M H, Zhao J R, Yang G H, Wang R H, Chen G P. Source-sink relationship and carbon-nitrogen metabolism of maize in different ecological regions and varieties. Sci Agric Sin, 2011, 44: 15851595 (in Chinese with English abstract).

[24] 高尚, 明博, 李璐璐, 谢瑞芝, 薛军, 侯鹏, 王克如, 李少昆. 黄淮海夏玉米籽粒脱水与气象因子的关系. 中国农业科学, 2018, 44: 1755-1763.

Gao S, Ming B, Li L L, Xie R Z, Xue J, Hou P, Wang K R, Li S K. Relationship between grain dehydration and meteorological factors in the Yellow-Huai-Hai rivers summer maize. Sci Agric Sin,
2018, 44: 1755-1763 (in Chinese with English abstract).

[25] 谭福忠, 韩翠波, 茐双利, 刘振江, 籍依安. 极早熟玉米品种 籽粒脱水特性的初步研究. 中国农学通报, 2008, 24(7): 161-168.

Tan Z F, Han C B, Zou S L, Liu Z J, Ji Y A. Elementary study on kernel dry-down traits in earliest-maturity maize hybrid. Chin Agric Sci Bull, 2008, 24(7): 161-168 (in Chinese with English abstract).

[26] Purdy J D, Crane P L. Inheritance of drying rate in mature corn (Zea mays L.). Crop Sci, 1967, 7: 294-297.

[27] Crane P L, Miles S R, Newman J E. Factors associated with varietal differences in rate of field drying in corn. Agron J, 1959, 51: 318-320.

[28] 问淑琴, 苏俊, 李春霞, 龚士琛, 宋锡章, 李国良, 扈光辉, 王 明泉, 贲利. 玉米籽粒灌浆、脱水速率的相关与通径分析. 黑 龙江农业科学, 2007, (4): 1-4.

Yan S Q, Su J, Li C X, Gong S C, Song X Z, Li G L, Hu G H, Wang $M$ Q, Ben L. Correlation analysis of dry-down and grain filling rate in maize. Heilongjiang Agric Sci, 2007, (4): 1-4 (in Chinese with English abstract).

[29] 雷蕾, 王威振, 方伟, 张子学, 刘正, 李文阳. 影响夏玉米生 理成熟后籽粒脱水的相关因素分析. 玉米科学, 2016, 24(3): 103-109.

Lei L, Wang W Z, Fang W, Zhang Z X, Liu Z, Li W Y. Analysis of factors affecting the kernel dehydrating after physiological mature in summer maize. J Maize Sci, 2016, 24(3): 103-109 (in Chinese with English abstract).

[30] 李璐璐, 明博, 谢瑞芝, 王克如, 侯鹏, 李少昆. 玉米品种穗 部性状差异及其对籽粒脱水的影响. 中国农业科学, 2018, 51: 1855-1867.

Li L L, Ming B, Xie R Z, Wang K R, Hou P, Li S K. Differences of ear characters in maize and their effects on grain dehydration. Sci Agric Sin, 2018, 51: 1855-1867 (in Chinese with English abstract).

[31] 张立国, 范骐骥, 陈喜昌, 李波, 张宇, 修丽丽. 玉米生理成 熟后籽粒脱水速率与主要农艺性状的相关分析. 黑龙江农业 科学, 2012, (3): 1-2.

Zhang L G, Fan Q J, Chen X C, Li B, Zhang Y, Xiu L L. Correlation analysis on dry-down rate and main agricultural traits in maize after physiological maturity. Heilongjiang Agric Sci, 2012, (3): 1-2 (in Chinese with English abstract). 